\title{
Correlation relationships between mechanical parameters of Bulgarian crushed-rock aggregates utilized in railway construction
}

\author{
Dimitar Fotev ${ }^{1}$, Roumyana Angelova ${ }^{2}$ \\ ${ }^{1}$ Ellatzite-Med PLC, 2086 Mirkovo,Sofia District,Bulgaria; e-mail: d.fotev@ellatzite-med.com. \\ ${ }^{2}$ Geological Institute, Bulgarian Academy of Sciences, Acad. G. Bonchev Str., Bl. 24, 1113 Sofia, Bulgaria; \\ e-mail: r_angelova@geology.bas.bg.
}

(Accepted in revised form: October 2017)

\begin{abstract}
Crushed-rock aggregates from 11 railway ballast-producing quarries in Bulgaria have been investigated. The test materials consist of igneous and sedimentary rocks of different ages: basaltic andesite, trachyte, diabase, andesitic tuff, quartz-cemented sandstone, dolomite and five varieties of limestone. The standard laboratory tests (Los Angeles, micro-Deval and point load) and in-situ test (Schmidt hammer) were carried out for determination of the following mechanical properties of aggregates: resistance to fragmentation; wear resistance; strength; and rock hardness. Results show that Los Angeles coefficient (LA) values range from $11.9 \%$ to $28.4 \%$. The micro-Deval coefficient $\left(\mathrm{M}_{\mathrm{DE}}\right)$ varies between $3.7 \%$ and $22.4 \%$. The point load strength index $\left(\mathrm{I}_{\mathrm{S}(50)}\right)$ is between 4.0 MPa and 8.8 MPa. The Schmidt hammer rebound value (SHV) ranges from 34.4 to 60.2. The possibility of predicting the Los Angeles and micro-Deval coefficients from the Schmidt hammer rebound value and the point load strength index was studied. Regression analysis shows a strong correlation between Los Angeles coefficient and point load strength index (coefficient of determination $\mathrm{R}^{2}=0.93$ ), a good correlation between the Los Angeles coefficient and the Schmidt hammer rebound value $\left(\mathrm{R}^{2}=0.62\right)$ and moderate correlation between the micro-Deval coefficient and the Schmidt hammer rebound value $\left(\mathrm{R}^{2}=0.51\right)$.
\end{abstract}

Fotev, D., Angelova, R. 2017. Correlation relationships between mechanical parameters of Bulgarian crushed-rock aggregates utilized in railway construction. Geologica Balcanica 46 (2), 17-21.

Keywords: crushed rock aggregates, Los Angeles test, micro-Deval test, point load test, Schmidt hammer test, regression analysis.

\section{INTRODUCTION}

When crushed, a variety of rocks are suitable for use as aggregates. Crushed-rock aggregates are the most common building material in Bulgaria. In railway transport, they are often applied in ballast construction. The ballast and its engineering behavior have a key role in governing the stability and performance of railway tracks. Ballast is a part of upper railway structure, which distributes the load from the railroad sleepers to the formation ground and facilitates surface water drainage (Lepoev, 2006). Aggregates for railway ballast must consist of hard rocks that do not wear out quickly under mechanical impact and are not easily susceptible to weathering. To perform these functions, ballast must be built of suitable material that complies with the latest standards and criteria (BS EN 13450:2013). Quality of the aggregates is deter- mined by the accomplishment of a series of physical and mechanical test methods.

Many publications in foreign scientific literature are devoted to correlation analyses between rocks' mechanical properties obtained by laboratory and in-situ tests (Ghosh and Srivastava, 1991; Aydin and Basu, 2005; Basu and Aydin, 2006; Kahraman and Gunaydin, 2007; Cobanglu and Celik, 2008; Ngerebara and Youdeowei, 2014; Wang et al., 2016; Ahmad et al., 2017; Azimian, 2017). In Bulgarian scientific literature, such an analysis has not been performed yet. In recent years, the geotechnical investigations of a variety of crushed-rock aggregates have been carried out in accordance with the new European standards (Fotev et al., 2014; Angelova et al., 2015).

The main objectives of this research are to analyze in detail the mechanical properties of rock aggregates from ballast-producing quarries in Bulgaria and to in- 
vestigate the possibility of predicting the Los Angeles and micro-Deval coefficients from results obtained by some simpler, indirect tests, such as the Schmidt hammer test and the point load strength test. Indirect tests are very easy to carry out, because they require smaller samples and simpler testing equipment, which is portable and can be used in the field. If a strong or good correlation relationship is found, the Los Angeles and micro-Deval coefficients of ballast aggregates could be evaluated by these quicker and more economical tests, at least for preliminary geotechnical investigations.

\section{TESTING MATERIALS AND METHODS}

The investigated rock material was collected from 11 railway ballast-producing quarries in Bulgaria (Fig. 1). The test materials consist of four igneous and seven sedimentary rocks: basaltic andesite, trachyte, diabase, andesitic tuff, quartz-cemented sandstone, dolomite and five varieties of limestone.

A number of laboratory tests were carried out for assessment of the aggregates' mechanical properties. Determination of resistance to fragmentation by the Los Angeles test method is governed by European Standard EN 1097-2:2010. The Los Angeles coefficient of all investigated railway ballast aggregates was calculated. The micro-Deval wear resistance test was carried out in accordance with the European Standard EN 1097-1:2011 and the micro-Deval coefficient was calculated. The point load test is not a direct way to measure rock strength, but an index test. ASTM Standard test method D 5731-08 was used for determination of the point load strength of rock aggregates and the point load strength index $\mathrm{I}_{\mathrm{S}(50)}$ was calculated.

The Schmidt hammer in-situ test was originally developed to compare the surface rebound hardness of concrete. Recently, this test has widely been applied for determination of rock hardness. The Schmidt hammer test was performed in the investigated quarries, following the instructions of the International Society of Rock Mechanics ISRM (1981). An L-type hammer with impact energy of $0.735 \mathrm{Nm}$ was used. ISRM suggested that 20 rebound values of SHV from single impacts separated by at least a plunger diameter should be recorded and the upper ten values averaged.

Regression analyses were performed to determine the empirical relations that mechanical parameters of the aggregates may have with the point load strength index and the Schmidt hammer rebound value.

\section{RESULTS AND DISCUSSION}

The obtained mechanical parameters of the investigated crushed-rock aggregates are presented in Table 1. The basaltic andesite from Gorno Ezerovo quarry and

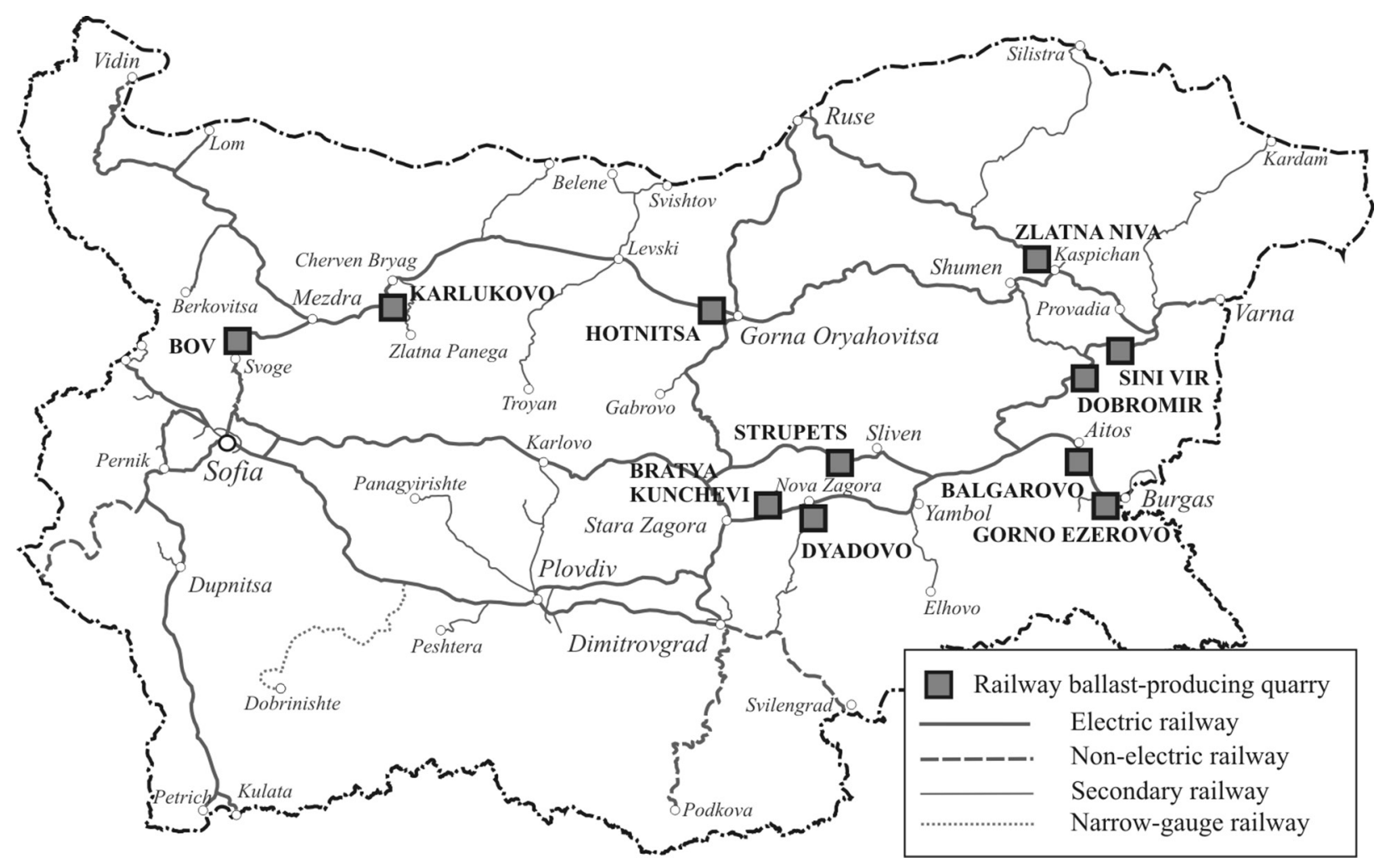

Fig. 1. Location of investigated railway ballast-producing quarries. 
Mechanical parameters of rock aggregates from ballast-producing quarries in Bulgaria

\begin{tabular}{llcccc}
\hline \multirow{2}{*}{ Quarry } & \multicolumn{1}{c}{ Rock type } & $\begin{array}{c}\text { Los Angeles } \\
\text { coefficient }\end{array}$ & $\begin{array}{c}\text { Micro-Deval } \\
\text { coefficient }\end{array}$ & $\begin{array}{c}\text { Schmidt } \\
\text { hammer } \\
\text { rebound value }\end{array}$ & $\begin{array}{c}\text { Point load } \\
\text { strength index }\end{array}$ \\
\cline { 3 - 6 } & & LA & $\mathrm{M}_{\mathrm{DE}}$ & $\mathrm{SHV}$ & $\mathrm{I}_{\mathrm{S}(50)}$ \\
\cline { 3 - 6 } Gorno Ezerovo & Basaltic andesite & 11.9 & 5.4 & 60.2 & $\mathrm{MPa}$ \\
Strupets & Quartz-cemented sandstone & 12.8 & 3.7 & 58.6 & 8.8 \\
Bov & Diabase & 15.7 & 14.6 & 48.9 & 7.4 \\
Balgarovo & Trachyte & 16.7 & 7.4 & 48.1 & 6.7 \\
Bratya Kunchevi & Andesitic tuff & 20.8 & 16.2 & 49.4 & 6.5 \\
Dyadovo & Dolomite & 19.9 & 11.0 & 53.3 & 4.4 \\
Karlukovo & Limestone & 19.5 & 7.9 & 40.0 & - \\
Dobromir & Limestone & 20.4 & 9.6 & 43.4 & 4.6 \\
Hotnitsa & Limestone & 22.3 & 8.6 & 54.1 & 4.6 \\
Sini Vir & Limestone & 27.0 & 21.6 & 39.5 & 4.1 \\
Zlatna Niva & Limestone & 28.4 & 22.4 & 34.4 & 4.0 \\
\hline
\end{tabular}

the quartz-cemented sandstone from Strupets quarry possess the highest resistance to fragmentation, highest resistance to wear and highest point load strength. The sandy limestone from Sini Vir quarry and porous limestone from Zlatna Niva quarry have the worst mechanical properties (Table 1).

The limestone from Karlukovo quarry is characterized by the best mechanical parameters compared with the other limestone varieties. The mechanical parameters' values of the andesitic tuff from Bratya Kunchevi quarry are very similar to the values of the sedimentary rocks (Table 1).

The possibility of predicting the LA and $\mathrm{M}_{\mathrm{DE}}$ coefficients from the Schmidt hammer rebound value and point load strength index of rock aggregates was

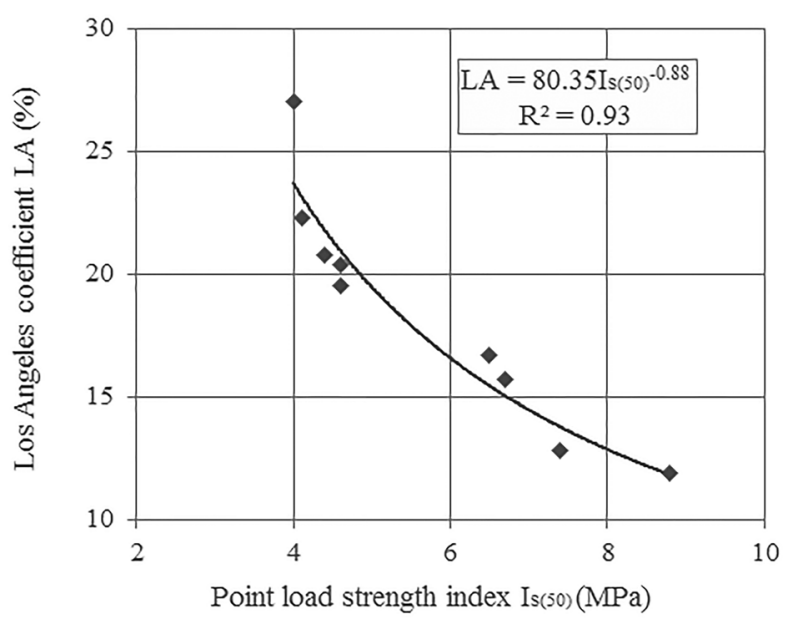

Fig. 2. Relationship between Los Angeles coefficient (\%) and point load strength index $(\mathrm{MPa})$ for tested rock aggregates. studied. The completed simple regression analysis based on the test results (Table 1) was performed and different fitting approximations were tried. The best approximation equation with the highest correlation coefficient was estimated for each regression.

An inverse relationship with a strong correlation (coefficient of determination $\mathrm{R}^{2}=0.93$ ) between the Los Angeles coefficient and the point load strength index was determined (Fig. 2). The relation between the micro-Deval coefficient and the point load strength index (Fig. 3) is also inverse, but the lowest correlation was obtained $\left(\mathrm{R}^{2}=0.41\right)$.

A linear negative relationship with a good correlation $\left(\mathrm{R}^{2}=0.62\right)$ between the Los Angeles coefficient and the Schmidt hammer rebound value (Fig. 4) was

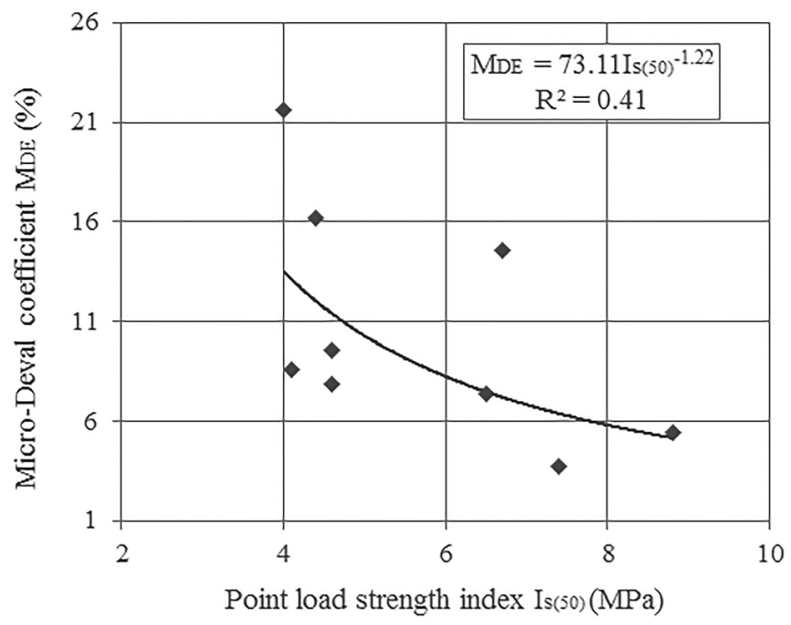

Fig. 3. Relationship between Micro-Deval coefficient (\%) and point load strength index (MPa) for tested rock aggregates. 


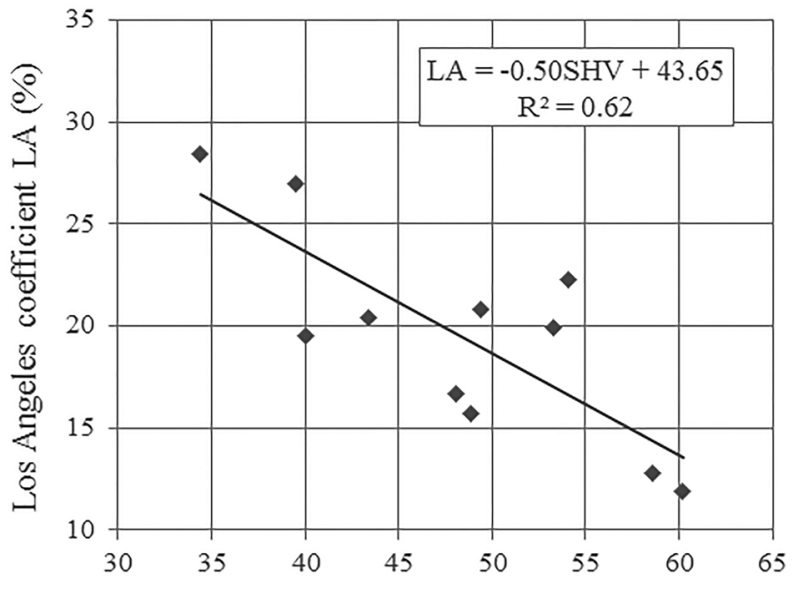

Schmidt hammer rebound value SHV

Fig. 4. Relationship between Los Angeles coefficient (\%) and Schmidt hammer rebound value for tested rock aggregates.

found. A linear negative relationship with a moderate correlation $\left(\mathrm{R}^{2}=0.51\right)$ between the micro-Deval coefficient and the Schmidt hammer rebound value (Fig. 5) was also determined. The results showed that correlations with the Schmidt hammer rebound value were not very strong but were good to moderate, nevertheless.

The obtained data on investigated crushed-rock aggregates prove that point load test is the best empirical method for predicting of Los Angeles resistance to fragmentation and correspond to research by other authors (Kahraman and Gunaydin, 2007). The point load test is a fast and uncomplicated method, and the field version of the point load apparatus can be used to predict a reliable Los Angeles coefficient in an early stage of a field geological and geotechnical survey.

\section{CONCLUSIONS}

A wide range of igneous and sedimentary rock aggregates with different mineral composition and fabric (basaltic andesite, trachyte, diabase, andesitic tuff, quartz-cemented sandstone, dolomite and five varie-

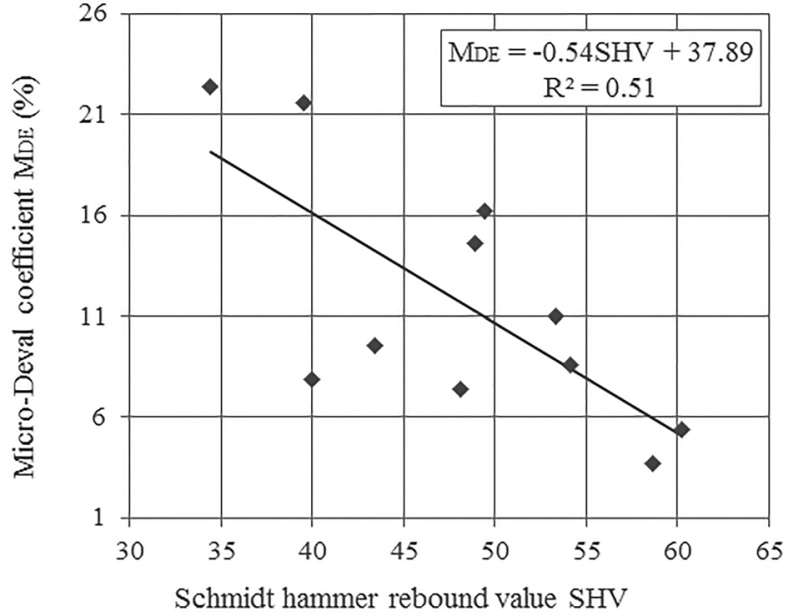

Fig. 5. Relationship between Micro-Deval coefficient (\%) and Schmidt hammer rebound value for tested rock aggregates.

ties of limestone) have been studied. The mechanical parameters of the investigated aggregates have been established in accordance with the latest European standards and criteria. The results from the Los Angeles abrasion test method and the micro-Deval wear test were statistically compared with the corresponding results from the Schmidt hammer in-situ test and the point load index test and prediction equations with strong to moderate correlation have been developed. The study confirms that the point load test is the best empirical method for predicting crushed-rock aggregates' Los Angeles resistance to fragmentation.

\section{Acknowledgments}

The authors are grateful to the Research and Design Center at the University of Architecture, Civil Engineering and Geodesy for their financial support of this study within the framework of contract BN 148-13 "Characteristics of Bulgarian rock aggregates for their application in the recent railway construction". The authors also wish to express their appreciation to Prof. Svetlozar Bakardjiev for his highly valuable advice on regression analysis.

\section{REFERENCES}

Ahmad, M., Ansari M., Sharma L., Singh R., Singh T. 2017. Correlation between Strength and Durability Indices of Rocks - Soft Computing Approach. Procedia Engineering 191, 458-466.
Angelova, R., Fotev D., Ivanova R. 2015. Geotechnical assessment of Bulgarian aggregates used for railway ballast construction. Review of the Bulgarian Geological Society 76 (1), 113-128 (in Bulgarian, with English abstract). 
ASTM D 5731-08: Standard Test Method for Determination of the Point Load Strength Index of Rock and Application to Rock Strength Classifications. ASTM International, West Conshohocken, PA, 2008, 12 pp.

Aydin, A., Basu A. 2005. The Schmidt hammer in rock material characterization. Engineering Geology 81, 1-14.

Azimian, A. 2017. Application of statistical methods for predicting uniaxial compressive strength of limestone rocks using nondestructive tests. Acta Geotechnica 12 (2), 321-333.

Basu, A., Aydin A. 2006. Predicting Uniaxial Compressive Strength by Point Load Test: Significance of Cone Penetration. Rock Mechanics and Rock Engineering 39 (5), 483-490.

Brown, E.T. (Ed). 1981. ISRM Suggested Methods - Rock Characterization Testing and Monitoring. Pergamon Press, Oxford, $211 \mathrm{pp}$.

BS EN 13450:2013: Rock aggregates for railway ballast. BIS, 33 pp. (in Bulgarian).

Cobanglu, I., Celik S. 2008. Estimation of uniaxial compressive strength from point load strength, Schmidt hardness and P-wave velocity. Bulletin of Engineering Geology and the Environment 67 (4), 491-498.

EN 1097-2:2010: Tests for mechanical and physical properties of aggregates. Part 2: Methods for the determination of resistance to fragmentation. CEN, Brussels, $34 \mathrm{pp}$.
EN 1097-1:2011: Tests for mechanical and physical properties of aggregates. Part 1: Determination of the resistance to wear (micro-Deval). CEN, Brussels, $14 \mathrm{pp}$.

Fotev, D., Varbanov R., Petrov B., Nankin R. 2014. Testing of aggregates of ballast beds in Bulgarian railway tracks in accordance with BS EN 13450:2013. Annual of the University of Architecture, Civil Engineering and Geodesy 46, 53-68 (in Bulgarian, with English abstract).

Ghosh, D., Srivastava M. 1991. Point-load strength: an index for classification of rock material. Bulletin of the International Association of Engineering Geology 44 (1), 27-33.

Kahraman, S., Gunaydin O. 2007. Empirical methods to predict the abrasion resistance of rock aggregates. Bulletin of Engineering Geology and the Environment 66 (4), 449-455.

Lepoev, M. 2006. Railway ballast layer as a structural element of the track bed. Railway Transport Magazine 5, 14-16 (in Bulgarian).

Ngerebara, O., Youdeowei P. 2014. Correlation of Mechanical Properties of Some Rocks in South-Eastern Nigeria. International Journal of Scientific and Research Publications 4 (2), 1-6.

Wang Hu, Hang Lin, Ping Cao. 2016. Correlation of UCS Rating with Schmidt Hammer Surface Hardness for Rock Mass Classification. Rock Mechanics and Rock Engineering 50, 195-203. 